\title{
REMOLINOS DE LA PAMPA. INDUSTRIA SALITRERA Y MOVIMIENTOS DE MUJERES (1910-193O)
}

\author{
Ana María Carrasco Gutiérrez
}

\section{* Introducción}

\section{Resumen}

Este artículo busca aportar a una mejor comprensión de lo que ha sido la participación socio-política femenina en el norte de Chile, a través de la visibilización de diversas expresiones y demandas de las mujeres nortinas a principios del siglo XX, cuando la magnitud de sus acciones tuvieron gran repercusión y resonancia a nivel nacional.

Se realiza un análisis desde el género, como categoría que permite rescatar lo político de las actuaciones colectivas de las mujeres de las actuales regiones I y XV, dando cuenta de su participación social y política durante la época salitrera, momento cuando sus acciones adquieren características que dejaron huella en el movimiento femenino chileno.

Se busca dar cuerpo a lo anterior recurriendo a fuentes escritas -libros, artículos e información de prensa- y orales como entrevistas en profundidad e historias de vida de mujeres nortinas.

Palabras claves: mujeres - participación sociopolítica - género - salitre norte de Chile.

\begin{abstract}
This article seeks to provide a better understanding of the women's socio-political participation in northern Chile, through the visibility of different expressions and demands of women in the early twentieth century when the relevance of their actions had great resonance and impact at a national level. A gender analysis is done as a category that

examines the political issues of the collective actions of women of the current I and XV Regions, to report on their social and political participation during the nitrate exploitation period when their actions acquired characteristics that left their mark on the Chilean women's movement. The above questions are explored through an examination of written sources (books, articles and information from the press). Oral sources are represented as in-depth interviews and life stories of
\end{abstract} northern women.

Key words: women - socio-political participation - gender - nitrate mining- northern Chile.

Recibido: julio 2014. Aceptado: octubre 2014.
Aun cuando hoy existe consenso que la historia de las mujeres resulta igual o más rica en acontecimientos que la de los hombres, es sólo en las últimas décadas cuando advertimos en la historiografía nacional interés por esta otra mitad de la humanidad. Incluyéndome entre las que buscan alcanzar una visión más globalizadora, problemática y verdadera de nuestra historia, es que he realizado este estudio, cuyo propósito central es contribuir a un mayor conocimiento sobre la participación política de las mujeres del norte de Chile durante las primeras décadas del siglo XX. Esto porque las mujeres nortinas, específicamente de la antigua región de Tarapacá (actuales XV y I regiones), han tenido un largo historial de lucha y participación social y política, característica que arranca desde principios de siglo, en la época del salitre, y que continúa hasta nuestros días a través de su alta presencia en distintas instancias organizativas, pero que se ha ocultado tras la historia oficial, que ha invisibilizado la existencia y fuerza de estos movimientos.

Sabemos que reconstruir la historia de la participación política femenina no es tarea fácil, pero queremos intentar salir de ese gran silencio que caracteriza su presencia al interior de los estudios sobre movimientos sociales, en donde, la mejor de las veces, aparecen en las luchas sólo como madres, esposas y/o compañeras. Nos centramos en la pampa salitrera, espacio que para muchos estudiosos/as representa el germen del movimiento femenino chileno. Es aquí donde las mujeres empiezan a incorporarse a las luchas sociales, dentro de un contexto social convulsionado en el que el movimiento obrero lleva la "bandera de lucha" y donde se crean las primeras organizaciones netamente femeninas $y / o$ feministas surgidas en nuestro país.

\footnotetext{
1 Departamento de Antropología, Facultad de Ciencias Sociales y Jurídicas (FACSOJUR), Universidad de Tarapacá. Av. 18 de Septiembre 2222, Arica. Chile. Email: amcarrasco@uta.cl
} 
El texto se organiza con la presentación del contexto en el cual se comienza a gestar el accionar colectivo de las mujeres del norte, que permite la generación de un movimiento que las vincula a las luchas sociales. Luego pasa a revisar las primeras organizaciones de mujeres creadas en la pampa salitrera, las Sociedades Mutualistas o de Socorros Mutuos, las Mancomunales y, finalmente, los Centros Femeninos Belén de Sárraga, considerados las instancias pioneras del feminismo en Chile.

\section{* Marco teórico-metodológico}

Para dar cuenta de lo anterior, se realiza el análisis desde el género, como una categoría que permite rescatar lo político de las actuaciones colectivas de las mujeres nortinas; evidenciando cómo la ideología conservadora las llama a la acción desde su rol tradicional de género pero obteniéndose, la mayor parte de las veces, como resultado nuevas formas de incorporación femenina a la política, a través de la diversidad, heterogeneidad, riqueza, incluso contradicción que presentan los movimientos de

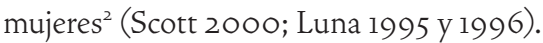

Se asume que la incorporación de esta categoría de análisis rescata contenidos de poder y subordinación presentes en la diferencia sexual, ${ }^{3}$ permitiendo identificar aspectos que tradicionalmente no son considerados en los estudios históricos que abordan la relación mujer y participación socio-política. Así, el género en tanto elemento de las relaciones de poder es lo que une las diferencias de clase, culturales y étnicas existentes entre las mujeres del norte de Chile y les permite constituirse en sujetos políticos a través de sus actuaciones en espacios participativos no tradicionales.

\footnotetext{
2 Se entenderán éstos de la manera que lo expresa Teresa Valdés (1994), es decir como un proceso social amplio que involucra un sinnúmero de actoras, individuales y colectivas, que se reúnen a partir de un problema compartido, una identidad común y una voluntad de acción transformadora. Su constitución comprende un conjunto de experiencias colectivas relativamente estructuradas, desarrolladas por mujeres, expresadas a través de acciones tanto comunitarias como sociales y públicas y que se plantea en lo individual y lo colectivo.

3 Ver Scott 1990; Luna 1994, 1995 y 1996, entre otros.
}

La metodología contempló tanto la utilización de fuentes primarias como secundarias. Dentro de estas últimas, se fichó y revisó material bibliográfico pertinente y accesible. Respecto a las fuentes primarias, se consultó documentación proveniente de distintos archivos. Por otra parte, se utilizó como uno de los principales materiales de consulta publicaciones periódicas, examinándose prensa escrita, principalmente de la zona norte. Otras de las herramientas metodológicas utilizadas fueron fuentes orales que permitieron enriquecer los antecedentes. Se analizaron entrevistas de mujeres nortinas, ${ }^{4}$ con el objeto de conocer la opinión e interpretación de algunas protagonistas respecto a los hechos consultados, como también para contrastar información ya registrada a través de fuentes escritas.

\section{* Incorporación de las mujeres pampinas A LAS luchas SOCIALES}

El norte chileno vive a principios del siglo XX un gran desarrollo económico, social y cultural, producto de la actividad salitrera, situación que genera una concentración de población en el área, especialmente de obreros, algunos con sus familias, que se radican en oficinas y campamentos creados para estos efectos y en los cuales se desarrolla una vida económica, social y cultural muy activa (González 2002).

“[... en Laguna también había filarmónica. La filarmónica era para los particulares aparte, para los tiznados aparte, para los empleados aparte, las invitaciones todas aparte porque a uno la invitaban para ir al baile, viene una comisión a preguntar a la casa, la que quiere ir queda inscrita, la que no sabía bailar había un día indicado para enseñarles [...] el vals, la polca, la mazurca, matine, polca troica. En las oficinas los bailes se hacían con piano y con orquesta, y en los campamentos que eran aparte se hacía con un acordeón grande o con la guitarra... En las orquestas usaban violin, el contrabajo, batería también" (Entrevista Sra. M. Á. C. Iquique, 1987).

Este contexto particular permite la reunión de las mujeres en torno a problemas compartidos en su condición de

4 Estas entrevistas fueron facilitadas por el Dr. Sergio González, sociólogo, especialista en la historia del salitre y amigo, a quien agradezco su gesto desinteresado y profesional. 
clase, que luego desembocarán en problemas de discriminación más específicos, como los de género, generándose un interesante movimiento de mujeres en estos parajes desérticos.

"[... ahi no faltaba nada, y el día que faltaba una cosa, la gente se iba a la pulpería y la pulpería era la que pagaba las consecuencias, cuando la mujer se organiza, compañero, anda muy bien la casa [...] habían compañeras que iban a la administración, sacaban al administrador de la oficina para afuera a que viniera a ver las cosas que sucedian, qué cosas no habian, esos eran movimientos de mujeres, el movimiento de mujeres fue muy lindo [...]" (Entrevista Sra. E. S. Iquique, 1987).

Producto de una serie de factores, a fines del siglo XIX y comienzos del XX se producen importantes cambios en la sociedad chilena, dentro de los cuales la incorporación de las mujeres a la fuerza de trabajo asalariado resulta fundamental. Este nuevo fenómeno, que también forma parte de la denominada "cuestión social", pasa a constituir un aspecto relevante de la bandera de lucha del movimiento obrero chileno, espacio reivindicativo donde a las mujeres se les "invita" a participar.

“[...] Decidnos compañeras: ¿acaso vosotras las esposas de los obreros pertenecéis a otra clase, que no a la de vuestros esposos o hermanos los obreros ¿Acaso también no sufrís y no sentís las mismas necesidades que nosotros los obreros? [...]".

Una de las características centrales que se pueden observar de este movimiento obrero es su impronta esencialmente masculina. Esta construcción realizada sobre la base de intereses netamente masculinos se advierte en el hecho de que si bien planteaban un cambio social radical, que por ende incluía la emancipación femenina, su discurso de fondo reproducía paradigmas hegemónicos, patriarcales y machistas, referentes a los roles de hombres y mujeres.

Las mujeres que se incorporan a este movimiento tuvieron dos opciones: asumir un papel de acompañantes para

5 Término acuñado a fines del siglo XIX y principios del XX, para aludir al conjunto de condiciones de vida de las clases populares, en contradicción con el estilo de vida oligarca.

6 José Zuzulich. Agrupación Obrero Socialista de Cholita. Diario El Despertar de los Trabajadores, 13 de junio de 1912. apoyar las reivindicaciones de los hombres, o intentar diferenciar la lucha femenina, articulando la opresión de género y de clase, conformando lo que fue denominado por algunos estudiosos/as como el "feminismo obrero" (Hutchison 1992 y 1995).

Para las mujeres que participaron en el movimiento obrero chileno, ya sea en organizaciones anarquistas y socialistas, la tarea fue difícil, debiendo enfrentar infinitas barreras y contratiempos, tales como resistencia por parte de los obreros para ser incluidas, su clara marginalidad dentro de las organizaciones obreras y la permanente ambigüedad sobre su doble identidad, como mujeres y trabajadoras. Pese a que las mujeres trabajadoras tuvieron una acción pública permanente, participando activamente en las protestas laborales e incluso habiendo sido responsables de muchas de las huelgas, su participación ha sido siempre catalogada de subordinada, no llegando a verdaderas posiciones de liderazgo o representación; más aún, sus intereses fueron generalmente representados ante el Estado y los empleadores por líderes masculinos, dirigentes, incluso por periodistas de la importante prensa escrita que operaba en esos tiempos (Carrasco 2007).

Ahora la situación y posición que les toca vivir a estas mujeres trabajadoras en lo que respecta a las luchas sociales obreras no es gratuita, tiene una razón de ser, un argumento que viene y se fundamenta a través de una ideología de género tradicional que asociaba -y aún asocia- la masculinidad con el trabajo y el espacio público y la feminidad con la domesticidad y el espacio privado. Así las concepciones vigentes en ese momento sobre la identidad del obrero y la mujer excluían implícitamente del movimiento a éstas y sus demandas. Pero esta marginalización "natural" del segmento femenino tenía consecuencias políticas directas para el movimiento obrero, ya que les restaba apoyo, fuerza, a las demandas masculinas, motivo por el cual son los propios dirigentes quienes adecúan estas normas para poder movilizar a las mujeres y tenerlas como aliadas.

Una de las formas de respaldo que las mujeres les podían otorgar era incorporándose a los movimientos laborales en los cuales participaban sus parientes masculinos. Los llamados a la participación de las hijas, hermanas, madres o esposas de los obreros, apelaban a la solidaridad materna, fraternal, familiar, invocando sólo a las características 
de las mujeres que derivaban de sus papeles domésticos, pese a que era una realidad la cantidad significativa de mujeres que se había incorporado a la fuerza de trabajo. Invitaciones dirigidas específicamente a las obreras, para que se unieran a las organizaciones laborales y reivindicaran desde éstas sus derechos como trabajadoras, eran muy escasas.

Según los principios contenidos en el Partido Demócrata,7 que se definía como la instancia que representaba los intereses de la clase obrera y de los oprimidos sin discriminación de raza, sexo o religión, las mujeres de clase trabajadora debían ser tratadas como camaradas en virtud de su condición de obreras. En éste, ellas trabajaron con relativa autonomía, pero siempre apoyadas de manera paternalista por Luis Emilio Recabarren y otros dirigentes demócratas, que consideraban necesaria esta permanente asesoría masculina, aun en aquellas organizaciones netamente femeninas (Hutchison 1995: 269).

Las mancomunales y sociedades de resistencia asociadas con el Partido Demócrata promovieron la participación de la mujer en la política laboral. Una de las situaciones más problemáticas que pusieron en el tapete fueron las formas específicas de explotación femenina en el lugar de trabajo, centrándose particularmente en los efectos nocivos que esta situación provocaba en las familias trabajadoras y en el movimiento sindical. Así, muchas las situaciones de injusticia que vivían las mujeres trabajadoras en sus lugares de trabajo fueron sacadas a la luz por el movimiento obrero pero no buscando, a través de estas evidencias, movilizar a las mujeres, sino más bien para que les sirviera como símbolo a los obreros para evidenciar la explotación capitalista. En el caso de los salarios, por ejemplo, si bien no son pocos los discursos que mencionan la exigua paga que reciben las mujeres, esta constatación estaba dirigida a argumentar una mejora de los salarios de los hombres y no defender el derecho de las mujeres a un salario más digno. Otro caso similar, que podríamos denominar de instrumentalización de la mujer obrera, se observa en lo que se refiere a las condiciones de trabajo, específicamente los lugares donde se

7 Partido político fundado el 20 de noviembre de 1887. Surge gracias a la iniciática de militantes del Partido Radical y representó los intereses de los trabajadores. desempeñaban laboralmente las mujeres, ya que se apelaba a éstos no sólo por la amenaza que pudieran significar a la mujer sino más bien vistos como amenaza a la salud y el bienestar de la familia.

Así, durante la primera década del siglo XX se advierte una gran preocupación por la "cuestión social" en todos los niveles del debate público, por lo que el tema de las mujeres obreras salta a la palestra teniéndose que reconocer la problemática femenina dentro de los lugares de trabajo, llevando a la clase dirigencial obrera a proponer instancias organizativas propias de las mujeres, lo que en el fondo redundaría en un fortalecimiento de los movimientos reivindicativos de los hombres.

La prensa obrera fue, sin dudas, un importante órgano de difusión al que pudieron acceder las trabajadoras asociadas al Partido Democrático que participaron en el movimiento obrero. En sus páginas fue frecuente encontrar llamados a las mujeres obreras a participar del movimiento, como también cierta cobertura a los problemas de éstas, aun cuando sus intereses específicos en tanto género no fueron representados como debían. Con todo, las mujeres aprovechan esta instancia para evidenciar la lucha femenina en contra de la opresión de clase y de género, abriéndose de este modo un espacio dentro el cual emergió un análisis más crítico del poder masculino sobre la mujer en el hogar, en el lugar de trabajo y en el movimiento obrero.

Este movimiento generado dentro del movimiento obrero mayor y definido como ya se ha dicho, "el feminismo obrero", ha sido considerado único en la historia de Chile. A través de éste se reconoció que las mujeres tenían demandas específicas (feministas) y comunes (de clase) que ameritaban la existencia de organizaciones de mujeres autónomas o en el mejor de los casos semiautónomas dentro del movimiento obrero. Pero si bien lo anterior era compartido por algunos líderes masculinos, hubo posiciones más radicales de parte de las feministas obreras, quienes pensaban que los trabajadores y dirigentes hombres jugaban un rol en la opresión de la mujer, por lo que resultaba absolutamente necesario para lograr la liberación femenina, la creación de organizaciones autónomas, en donde los hombres podían jugar sólo un papel secundario, de apoyo hacia ellas (Hutchison 1992 y 1995). 
Se buscaba, en el fondo, revertir la pasividad femenina y la manipulación de que eran objeto por parte de los obreros, observable cuanto éstas participaban en el movimiento obrero, ya que si bien estaban conscientes de que las mujeres no eran activas en pro de su propia defensa, esta actitud tenía que ver con las cortapisas impuestas por los hombres quienes, conscientes o inconscientemente, estaban involucrados en su opresión. Esto argumentado, básicamente, en la actitud que los hombres tenían frente a sus compañeras obreras, las cuales sistemáticamente eran condicionadas a ceder a las demandas de clase por sobre las de género, siendo constantemente ridiculizadas en sus intentos de lucha, como también por la negación permanente de la clave que ellas buscaban para su emancipación: la educación.

Muchas de las líderes del movimiento feminista obrero (Carmela Jeria, Esther Valdés de Díaz, entre otras) argüían que las mujeres podían reivindicar sus derechos a través de la educación, la organización y la acción militante propia, pese a las barreras que efectivamente existían para la participación de la mujer en la política laboral que se desarrollaba en el marco de un movimiento obrero dominado por los hombres (Hutchison 1995: 274).

Ahora, pese a los esfuerzos desplegados por las feministas obreras para romper con la tradicional creencia respecto a los roles de género asignados, siempre mantuvieron el espacio doméstico como parte del ideal femenino, así tanto el trabajo asalariado como la domesticidad eran espacios complementarios. Constituyendo siempre, desde esta perspectiva, las trabajadoras una fuerza de trabajo secundaria que, con el tiempo les permitiría volver a su lugar natural dentro de la esfera doméstica.

No obstante las falencias que hoy podemos encontrar en este movimiento, que sin dudas apenas esbozó el tema de las relaciones de poder entre hombres y mujeres, fue efectivo en el sentido de proporcionar una tribuna desde la cual se pudieron revelar las numerosas y variadas formas de dominación masculina frente a las mujeres.

Ya hacia 1908, nos encontramos con una interesante visibilidad del feminismo obrero y un número considerable de sociedades de resistencia, surgidas como resultado de los esfuerzos educativos y propagandísticos que se venían dando, pero con muy pocas asociaciones consolidadas y legitimadas que hubiesen logrado obtener respuestas efectivas a sus demandas por parte de los empleadores.

Así, con posterioridad a 1908 el feminismo obrero perdió la fuerza que había alcanzado. Las obreras fueron incorporadas en una posición marginal a las federaciones obreras, perdiéndose esa complementariedad entre géneros que se había dado anteriormente.

El feminismo obrero aparentemente desapareció con el desmoronamiento de las asociaciones femeninas autónomas. Las mujeres, a partir de los años 1920, comienzan a agruparse en los Consejos Femeninos de la Federación Obrera de Chile (FOCH).

Dentro de estas nuevas instancias se canaliza la participación de las mujeres. Recabarren, líder de la FOCH, promueve el papel público de las mujeres, haciendo de las actividades educacionales y culturales el espacio adecuado para contener la presencia femenina. Recabarren promovió la intervención femenina en el cambio político pero - como su visión descansaba fuertemente en un concepto de feminidad definido a partir de las actividades domésticas- ubicó su fuerza en el ser madre de la clase trabajadora, hermana de lucha de los trabajadores o amante del movimiento socialista.

"Él [Recabarren] fue el primero que tuvo la iniciativa sobre organizaciones femeninas, porque él dio la pauta sobre cómo se organizaran las mujeres... al interior de la FOCH, hombres y mujeres, jóvenes y viejos... hasta las señoras de edad tenían sus organizaciones. Trabajábamos con él. [...] Las primeras organizaciones las organizamos nosotros, el Partido fue el que dio la organización para eso. Formábamos comités en la pampa, en los pueblos, en todas partes. Anita Tapia fue la primera mujer que vino al norte a organizar los comités" (Entrevista Sra. E. S. Iquique, 1987).

\section{* Primeras organizaciones femeninas}

Si bien en este momento encontramos en el ambiente nacional una fuerte influencia de ideologías externas que plantean y propician la existencia de una sociedad más igualitaria, también es posible identificar ciertos factores particulares y locales que habrían facilitado el movimiento de mujeres en la pampa nortina. Dentro de éstos y tomando lo planteado por otros investigadores (Castro 
1994; González 2002), entre ellos Julieta Kirkwood (1990: 105-109) podemos mencionar:

1. El gran desarrollo del movimiento obrero en la zona salitrera, que revistió características particulares y posibilitó una importante y destacada participación de las mujeres en los campamentos, acompañando, alentando, apoyando y alimentando a los trabajadores (padres, maridos, hermanos, hijos, parientes) en las protestas, huelgas y manifestaciones en pro de los derechos de éstos.

2.El surgimiento del Partido Obrero Socialista (POS) en 1912, quien desplegó, bajo la orientación de Luis Emilio Recabarren, una interesante actividad de difusión hacia la mujer, promoviendo el desarrollo intelectual de ésta y su participación en organizaciones, a través de la prensa escrita, charlas, manifestaciones y eventos culturales.

3. La presencia en Chile de Belén de Sárraga, conferencista española, librepensadora y anticlerical, que alentó a las mujeres a organizarse y dar vida a la reivindicación emancipatoria y que tuvo una especial llegada ideológica entre las mujeres chilenas, en especial las de la zona norte salitrera.

Si nos remitimos a lo que era el movimiento femenino en el norte de Chile, nos encontramos que en las primeras décadas del siglo XX está la presencia de mujeres proletarias, trabajadoras, esposas, hermanas e hijas de obreros del salitre que se reúnen y organizan para denunciar las injusticias que viven en tanto clase y género. Esto a diferencia de lo que ocurría en el centro del país, principalmente en Santiago, donde en este mismo momento, surgen Centros Femeninos en los que mujeres de clase alta son las que -apegándose al orden establecido - "solicitan" mejoras en su condición. Vemos entonces dos realidades distintas, dos estrategias políticas diferentes, pero para un objetivo de fondo similar, cual es evidenciar la universalidad de la opresión de la mujer, sea en el tema de la educación y la cultura, en la lucha de clases, en la reglamentación de la vida sexual, de la moral, etc.

Obviamente la condición sometida en la que se encontraban las mujeres de la pampa nortina dista mucho a la situación vivida por las mujeres santiaguinas donde, las que comienzan a luchar por los derechos de las mujeres son aquellas que ocupan espacios privilegiados en la estructura social de nuestro país.

En el norte, recordemos que la economía salitrera provocó una concentración proletaria en la pampa, espacio donde se crean los "pueblos", "oficinas" y "campamentos", en donde prevalece el aislamiento habiendo una total ausencia de redes familiares -aspecto central en el acomodo de los migrantes en nuevos espacios- lo que sin dudas influyó y permitió el desarrollo de la solidaridad que se construye entre la clase obrera y entre los obreros y sus familias nucleares, especialmente entre los obreros y sus mujeres (González 1991 y 2002). Las condiciones de vida que los acercaban al trabajo incesante, la miseria, las enfermedades, la muerte cotidiana, hacía que este sector fuese el centro de la presión nacional; donde la clase trabajadora expresaba su rebeldía y donde también era violentamente reprimida.

Sabemos que las mujeres populares siempre han tenido una estrecha relación con el abastecimiento alimenticio para el hogar, característica que se hace más fuerte en las oficinas y campamentos de la pampa salitrera, motivo por el cual ellas jugarán, en este espacio, un rol fundamental en las acciones, huelgas, manifestaciones que dicen relación con la carestía de la vida.

"Antes la mujer luchaba y peleaba. En las pulperías no podía faltarle leña y el carbón porque la gente hacía el movimiento al tiro. Cuando escaseaban los alimentos, no había carbón ni leña, las mujeres paraban las máquinas con los trabajadores, le ponían así en las líneas, no pasaban los camiones. [...] cuando las huelgas se hacían venía la gente. Fue muy bonito el movimiento ese" (Entrevista Sra. S. M. Iquique, 1987).

Las exigencias de la vida diaria, las energías puestas en la sobrevivencia cotidiana, las tareas alimenticias y domésticas, hacen que la mayor parte de estas mujeres, inicialmente, no se cuestionaran políticamente la sociedad en la cual vivían y menos aún la supremacía masculina. Por el contrario, toda su energía fue puesta en apoyar incondicionalmente al hombre, compañero, trabajador, obrero, encargado del trabajo productivo que permitía la sobrevivencia económica de la familia.

En el contexto descrito las mujeres de la pampa nortina, mujeres populares, no se encontraban del todo aisladas y fuera de la conciencia feminista que ya a comienzos del 
siglo XX se hacía sentir con fuerza en las clases altas y posteriormente medias del centro del país. Esto principalmente porque dentro de la concepción obrera anarquista, lo internacional tenía gran importancia, lo que hace que circule permanentemente en la prensa o boletines locales, información sobre acontecimientos externos, en este caso sobre el movimiento sufragista (Kirkwood 1987: 100). Por otra parte, las mujeres de las salitreras no eran entes pasivos frente a las injusticias que vivían, ellas alentaban a los hombres-obreros a la lucha, muchas veces las fomentaron y en otros momentos críticos estaban ahí de cuerpo presente, con sus hijos a cuesta, apoyando las huelgas y alimentando a los trabajadores. Esta postura combativa y revolucionaria de la mujer popular, que apoyó fuertemente el movimiento obrero con expresiones típicamente femeninas y que encontramos como una constante en el norte salitrero, no es posible generalizarla a nivel nacional.

Con todo y para ordenar nuestra revisión sobre las acciones colectivas e instancias organizativas femeninas que se crearon en el norte salitrero, debemos partir diciendo que una de las primeras manifestaciones las encontramos de manera paralela al calor de la organización y lucha del movimiento obrero. Se crean, en algunos casos, como organizaciones independientes a los mismos organismos que la clase obrera crea para dar respuestas a sus necesidades.

\section{Sociedades mutualistas o de socorros mutuos}

Los inicios de las organizaciones de mujeres en el norte salitrero se remontan a fines del siglo pasado, con la fundación de sociedades de auxilio y ayuda mutua. Se trataba fundamentalmente de Sociedades de Señoras, insertas en el movimiento mutualista de la época y cuyo objetivo principal era el "socorro mutuo", es decir, el bienestar social y económico de las socias y sus familias.

El mutualismo fue la primera tendencia de organización de los sectores obreros del país, desde mediados del siglo XIX. La asociación de trabajadores de un mismo gremio tenía por objetivo salvar de manera conjunta los obstáculos de diversa índole que se les presentaban a los socios. Las difíciles condiciones de vida que debían enfrentar, en este caso los obreros del salitre, la indefensión laboral en la que se encontraban frente al despido o a la enfermedad y el desamparo en que quedaban las viudas e hijos de los obreros tras su deceso, fueron los motivos que promovieron la rápida expansión de las sociedades de socorros mutuos.

Vemos entonces que las "sociedades mutualistas" o de "socorros mutuos" fueron las primeras organizaciones femeninas preocupadas de solucionar problemas inmediatos de sus asociadas. Jurídicamente se definen como una forma perfeccionada de asociación, basada en la reciprocidad de servicios y donde los individuos están sujetos a leyes comunes (Cáceres 1938: 36). Los principios fundamentales por los cuales se crean son la ayuda mutua y el fomento del ahorro.

Estaban constituidas por dueñas de casa y obreras en general que buscaban en esta instancia apoyo de carácter más bien económico ante la adversidad. Se preocupaban de otorgar a la asociada ayuda en salud -a través de la entrega de subsidios médicos-, cancelación de gastos de funerales y acceso a un mausoleo, un lugar de reuniones. La familia de la asociada también se beneficiaba después del deceso de está ya que se le entregaba un subsidio monetario, por una sola vez, para paliar la complicada situación económica en que, generalmente, se quedaba después de esta trágica situación.

El ingreso era voluntario por lo que las socias permanecían el tiempo que ellas desearan. Cualquier mujer podía ingresar siempre y cuando tuviera un mínimo de edad de 15 años y un máximo aproximado de 45 años. Exigencia del ingreso era un permiso otorgado por los padres - en los caso de las menores de edad- y del marido para las casadas, un examen de salud y antecedentes sobre la honorabilidad y moralidad de la postulante. Cada integrante aportaba mensualmente una cantidad de dinero que le permitía a la organización la entrega de diversos beneficios, en los que además de los materiales se incorporaban la preocupación institucional por el perfeccionamiento moral y educacional de sus asociadas (Conte 1987: 74). Una forma de aumentar los ingresos de la organización era la realización de actividades, tales como beneficios, rifas y comidas.

Estas formas de agrupación femenina no permitían ningún tipo de proselitismo, fuera político o religioso, aspecto que marca diferencia con las organizaciones propiamente obreras.

Las integrantes de estas sociedades mutualistas femeninas se caracterizaban fundamentalmente por tener, por 
un lado, una situación económica inestable; y por otro, por contar con una escasa preparación intelectual. Muchas de ellas surgen tempranamente, con anterioridad a la fecha que aquí nos interesa, pero se mantienen vigentes por muchos años, incluso hasta hoy. ${ }^{8}$

El auge de este tipo de organizaciones lo encontramos en el decenio 1900-1910,9 siguiendo con una presencia importante hasta las dos primeras décadas del siglo XX (Cruzat 1980), creándose una serie de estas instancias incluso en las oficinas salitreras.

\section{"Oficina Centro Lagunas. Nueva Sociedad de Señoras}

Entre las señoras de esta oficina se ha organizado una sociedad cuyo nombre y directorio es como sigue:

Sociedad Protectora de Señoras de Socorros Mutuos de la oficina Centro Lagunas.

Deseamos prosperidad y buenos rumbos a la naciente institución"."10

Este proceso de expansión se debe principalmente a que eran el único medio de previsión existente. En 1924 se crean las Cajas de Seguro, ${ }^{11}$ perdiendo los socorros mu-

8 Por ejemplo, el 16 de julio de 1894 se crean en Iquique la "Sociedad Internacional Protectora de Señoras de Iquique" (Diario El Tarapacá, 16 de julio de 1924) y ese mismo año, el $1^{\circ}$ de enero, la "Sociedad de Obreras Sudamericanas de Iquique"; ambas consideradas dentro de las más antiguas del país. Luego, el 22 de febrero de 1897 "La Unión Fraternal de Obreras" y en esa misma fecha es fundada la "Sociedad Progreso Social de Señoras, en Iquique" (Diario El Tarapacá, 18 de mayo de 1924); en 1899, el ocho de octubre, encontramos la "Unión Universal de Señoras"; el 10 de octubre de 1900 la "Auxiliadora Chilena de Señoras"; y el 13 de junio de 1901 se crea la "Sociedad Emancipadora de la Mujer en Iquique", cuya directiva estaba formada por Grisela Mendoza G. y Lastenia Grandón (Diario El Trabajo, 5 de abril de 1902); también en este año nace la "Sociedad Hermanas del Trabajo" (Diario El Nacional, 20 de octubre de 1913) y la "Liga Obrera", fundada el 19 de mayo de 1901; para 1902, es posible encontrar mencionadas en la prensa local varias otras ya en funcionamiento, por ejemplo "La Sociedad de Señoras n 1 y Socorros Mutuos de Huantajaya", que crearía una delegación de esta entidad en "el puerto de Santa Rosa" (Diario El Trabajo, 9 de agosto de 1902 y 30 de agosto de 1902), etc.

9 "El Congreso Social Obrero habla de representar 168 sociedades en 1902, cifra que aumenta hasta llegar a 433 en 1910". Tomado de Cruzat, op. cit. 1980: 15 .

10 Diario El Despertar de los Trabajadores, 23 de enero de 1913.

${ }^{11}$ El 8 de septiembre de 1924, fue a probada la Ley 4054, Sobre tuos su preponderancia, aun cuando no desaparecen completamente, ya que siguen prestando una importante labor en beneficio de los más desposeídos.

Estas sociedades eran consideradas por las mujeres más progresistas como espacios no aprovechados para reivindicar los derechos de las mujeres. Se les ve como instancias donde las mujeres hacen actividades sin sentido práctico para el bien y el mejoramiento de la condición y situación de las mujeres. No se interesan en el aprendizaje de derechos y deberes femeninos, para liberarse del yugo que oprime a las mujeres, especialmente las trabajadoras. Con todo, constituyen sin duda espacios de participación e integración social de mujeres proletarias y de clase media-baja.

Las asociaciones locales de ayuda mutua que movilizaron a las mujeres a comienzos del siglo pasado van quedando rezagadas con la aparición de sindicatos mixtos y de mujeres, luego de la expansión del movimiento obrero. Esto nos demuestra el inicio de un mayor activismo femenino.

\section{Mancomunales}

Dijimos que el mutualismo tuvo como objetivo fundamental mejorar el nivel de vida de sus asociados. Estas primeras asociaciones "gremiales", derivaron en las llamadas "sociedades mancomunales", organizaciones que conservaron los fines de ayuda mutua introduciendo también nuevos elementos como la lucha por el mejoramiento de las condiciones laborales de los obreros y la conciencia de clase entre sus miembros.

Existen diferencias entre el mutualismo y el movimiento mancomunal, pero ambas corrientes comparten objetivos de socorros mutuos y reivindicaciones económicas.

En el norte chileno, las mancomunales tuvieron una fuerte presencia. El movimiento mancomunal tomó rápido desarrollo en el sector de minas y en las oficinas salitreras. En cuanto a su composición interna, sus miembros pertenecían a la clase trabajadora, siendo fundamentalmente individuos que trabajaban en el puerto

Seguro Obligatorio de Enfermedad e Invalidez. Esta ley crea las Cajas de Seguro Obrero. 
o en la pampa, provenientes en su mayoría del sur o la zona central, también peruanos o bolivianos. Si bien mayoritariamente eran hombres, también había mujeres que trabajaban y ejercían algún oficio.

Tenemos, entonces, que dentro de otros aspectos, estas instancias buscaron la incorporación de las mujeres en sus actividades, jugando un importante papel en esta postura Recabarren. Si bien inicialmente apelaron a la mujer en su calidad de hermana y esposa del obrero, luego se les llama a incorporarse como trabajadoras y participar con los hombres en el movimiento, para que lucharan directamente por sus problemáticas, tales como la educación y los sueldos. En definitiva, vieron en las mujeres un apoyo en su lucha por el socialismo.

La primera organización sindical en el país es la Combinación Mancomunal de Obreros, fundada en enero de 1900 por el gremio de lancheros de Iquique. ${ }^{12}$ Dentro de los estatutos de la Combinación Mancomunal de Obreros, se estipula que la mujer tiene derecho a solicitar su incorporación.

Dentro de las mancomunales algunas dirigentas participan en el directorio, junto con los hombres. También, a través de las mancomunales, que a partir del año 1905 se crean en Iquique, Tocopilla, Antofagasta, Taltal y Chañaral, se forman "gremios de señoras" afiliados a la Combinación, gremios que participaba de la orgánica de la mancomunal al interior del Congreso o Cámara del Trabajo, con un número similar de representantes que el que tenían los otros gremios insertos, como ser el de los artesanos, mineros y marítimo (Castro 1994: 20). En este caso las participantes o socias eran fundamentalmente las esposas de los obreros mancomunados.

Si bien el propósito central e inicial de estas instancias era evidenciar la paupérrima situación económica de los trabajadores y sus familias, al poco andar se pasa a ampliar las reivindicaciones, incorporándose la conciencia de la opresión social y política que sufre el proletariado.

${ }^{12}$ Esta instancia organizativa agrupa a diferentes gremios, primero del norte y luego de todo el país. Su creación es apoyada e impulsada por Luis Emilio Recabarren, siendo sus objetivos centrales los de estimular el socorro mutuo, como asimismo y paralelamente combatir por las transformaciones de las relaciones entre obreros y patrones.
La función que realizan es amplia y va desde organizar a los obreros para combatir mancomunadamente los males que le aquejaban, fomentar la solidaridad, proteger a sus afiliados con ayuda asistencial, promover la enseñanza a través de la apertura de escuelas, alejar a los obreros de los vicios por intermedio de las filarmónicas, centros sociales y artísticos. Con todo, busca lograr un equilibrio entre la tradición mutual que imperaba con fuerza en ese momento y que había comenzado con anterioridad, y las necesidades del movimiento proletario (Ortiz 1985: 191).

Estos cambios y nueva mirada al objetivo de estas organizaciones que para la mayor parte de las mujeres que inicialmente participaban en los "gremios de señoras" eran la organización, la ilustración y la ayuda mutua, se agrega la reivindicación de su emancipación.

Ahora, una de las primeras organizaciones de mujeres obreras del norte fue la "Sociedad de Obreras, Instrucción y Socorros Mutuos N 1" fundada en 1894 en Antofagasta y teniendo a su cabeza a Eloísa Zurita Arriagada de Vergara, quien fue delegada al Congreso Social Obrero en Concepción en 1907, participando igualmente en varios encuentros obreros realizados a lo largo del país y siendo importante y permanente colaboradora de la prensa obrera, espacio que aprovecha para manifestar su apoyo al movimiento obrero y reflexionar sobre la condición femenina desde la mujer proletaria y su explotación (Salinas 1987: 40-41).

El 13 de junio de 1901 se funda la Sociedad Emancipación de la Mujer en la ciudad de Iquique. En 1903 encontramos a esta organización participando del óbolo que las organizaciones obreras de esta ciudad nortina realizaron para ir en ayuda de las víctimas de la represión a una huelga en Valparaíso (Diario El Trabajo, 8 de agosto de 1903). No tenemos noticias sobre posteriores actividades ni sobre su duración en el tiempo, que parece no haber sido muy larga.

En 1902 sabemos de la existencia de la "Sociedad de Señoras $N^{\circ} 1$ y Socorros Mutuos de Huantajaya" (Diario El Trabajo, 9 de agosto de 1902).

Otra organización de temprana data en el norte es la "Combinación de Señoras Instrucción y Socorro Mutuo" 
creada en Tocopilla en 1906. Su presidenta fue Rudecinda Venegas y contó en sus comienzos con 120 socias (Diario El Proletario, 1 de junio de 1906). Dentro de sus acciones destacadas está el haber establecido delegaciones en cada una de las oficinas salitreras de la pampa y creado una Escuela Diurna y Nocturna de Niñas, en Tocopilla. Por otra parte y siguiendo los objetivos de la Combinación Mancomunal de Obreros, además del tema de la instrucción, estipula la ayuda de las socias en caso de enfermedad y cuota mortuoria a la familia, en caso de deceso. A través del periódico obrero "El Proletario" difunden su accionar. Esta organización se disuelve a fines de 1906, estando activa sólo algo más de seis meses, siendo disuelta por orden legal.

Necesario es mencionar que los estudios sobre el mancomunalismo en el norte salitrero no profundizan en las sociedades femeninas existentes en aquella época, sólo se limitan a dar algunos datos sobre éstas. Por otro lado, hay que señalar que existen pocas fuentes para indagar en este período, siendo lo periódicos de las combinaciones mancomunales el principal medio de información de los objetivos, principios y actividades de las organizaciones.

En la ciudad de Iquique existían varias sociedades de mujeres - ya mencionadas dentro de las organizaciones mutualistas- fundadas en la última década del siglo XIX y en funcionamiento hacia 1910, pero por la escasa información que se cuenta, no es posible saber si estas organizaciones femeninas vivieron la transición desde el mutualismo hacia las sociedades mancomunales que vivieron las sociedades de varones en esa época. Es presumible, sin embargo, que estas organizaciones hayan estado más cercanas al mutualismo, pues tanto su persistencia en el tiempo como las actividades organizadas por éstas así lo estarían demostrando. Asimismo, sus objetivos y principios parecen haber estado cercanos al bienestar social y "adelanto" de las socias, siempre inspirado en el espíritu de solidaridad social característico del mutualismo.

Las organizaciones de este período, en la ciudad de Iquique, que persistieron en el tiempo fueron: "Sociedad Obreras Sudamericana", "Sociedad Unión Universal de Señoras", "Sociedad Auxiliadora Chilena de Señoras", "Sociedad Progreso Social de Señoras", "Sociedad Inter- nacional Protectora de Señoras". De ellas tenemos información de sus actividades en beneficio de sus socias, así como de la celebración de sus aniversarios durante casi toda la primera mitad del siglo.

Con todo, respecto a la organización de obreras y trabajadoras, es posible advertir como una característica predominante de la zona norte la reducida presencia de éstas en expresiones político partidarias o gremiales reivindicativas propias. Su participación fuerte se da al lado del obrero, soportando y apoyando el peso de las huelgas y manifestaciones que en las primeras décadas del siglo XX eran frecuentes.

El período que sigue a 1910 y hasta aproximadamente 1925 es posible caracterizarlo por la irrupción paulatina de organizaciones de mujeres insertas en el movimiento político de la época. Así por ejemplo, vemos que la tendencia socialista se hace presente con bastante fuerza entre las mujeres de la zona salitrera. Por otro lado, se constata la presencia continua de las "organizaciones de socorros mutuos", que se proyectan durante todo este período, cubriendo necesidades de asistencia social entre muchas mujeres.

La principal fuente de información para esta época en la zona salitrera es el periódico El Despertar de los Trabajadores, publicado en la ciudad de Iquique. Fundado y dirigido en sus primeros tiempos por Luis Emilio Recabarren, en sus páginas siempre mostró un particular interés en la problemática de la mujer, publicando desde sus inicios artículos sobre la situación de la mujer, los que en su mayor parte eran escritos por hombres. También se difundieron noticias sobre las sufragistas inglesas y sus actividades en pro del voto femenino.

En estos artículos se aprecia una cierta mirada "paternalista" hacia la mujer, enfatizando la necesidad de "educarla" e "instruirla", así como también de sacarla del oscurantismo y "liberarla" de la influencia de la Iglesia Católica y el clero. También observamos en estos discursos la presencia de imágenes y estereotipos en relación a la mujer, su carácter y conducta: "...es infinitamente sentimental y egoísta” (Diario El Despertar de los Trabajadores, 27 de enero de 1912). Se suele resaltar también su condición de madre y formadora de las nuevas generaciones. 
De igual forma se dieron a conocer textos literarios firmados por mujeres, ${ }^{13}$ que daban a conocer los problemas de la vida en las salitreras, como por ejemplo el alcoholismo de los hombres de la zona y sus estragos entre las familias. A lo largo de todo este período observamos el desarrollo progresivo de una conciencia de clase entre las mujeres nortinas.

\section{* Centros Femeninos Belén de Sárraga}

Las primeras instituciones netamente femeninas surgidas en nuestro país son los Centros Femeninos Belén de Sárraga, que se crean a partir de 1913 en la zona norte, específicamente en Iquique, Antofagasta y las principales oficinas salitreras. Estas instancias organizativas de mujeres, consideradas puntos de partida para el feminismo en Chile, cobran vida luego de la visita de Belén de Sárraga ${ }^{14}$ conferencista española.

Si bien en la primera década del siglo XX nos encontramos con una serie de personajes extranjeros que recorren el país difundiendo ideas influenciadas por el anarquismo y el librepensamiento, es Belén de Sárraga la que dejará huellas con su presencia. Su visita impactó fuertemente en el mundo obrero nortino, especialmente entre las mujeres, quienes vieron en el anticlericalismo de la española una respuesta a la molestia que existía frente a las posiciones de la iglesia y el clero católico, a quienes se culpaba por el "atraso" en que se encontraban las mujeres

\footnotetext{
${ }^{13}$ Hay que tener cuidado con estas firmas porque Recabarren publicaba algunos artículos con seudónimo femenino. Se sabe, por ejemplo, que "Dora Vals" correspondía al seudónimo de Salvador Barra Wöll.

14 Belén de Sárraga nació el 10 de julio de 1873 en Vallado-
} lid. Belén pasa parte de su infancia en Puerto Rico; regresa a España a cursar sus estudios, graduándose de Profesora y Doctora en Medicina en la Universidad de Barcelona. Desde su adolescencia y viviendo en medio de un ambiente de represión monárquica, Belén fue una apasionada propagandista de ideas libertarias. Funda, en 1896, la Asociación del Pensamiento Libre en Málaga, influida por el pensamiento progresista liberal, dirige el periódico La Conciencia Libre que es distribuido a Barcelona y Valencia. Simpatizaba con el Partido Republicano Federal, fundado por Francisco Pi y Margall. Además, a comienzos del siglo XX se vio fuertemente influida por el movimiento obrero español y europeo, liderado por los anarquistas y primeros grupos socialistas (Vitale y Antivilo 2000: 30-31). de la época. El anticlericalismo y el llamado "librepensamiento", fue una importante fuente de conjunción de fuerzas obreras en general y femeninas en particular.

Su llegada a Latinoamérica es en 1912, siendo Uruguay el centro de operaciones para su programa de visitas que contemplan distintos países y que tienen por objeto difundir sus ideas de librepensamiento, anticlericalismo y emancipación de la mujer.

\section{"La llegada de Belén de Zárraga tiene para los pueblos Americanos extraordinaria trascendencia, pues ella trae la noble misión de edu- car con la palabra, mostrándole el sendero verdadero de la mujer, hoy día esclava de perjudiciales y funestísimas costumbres que sólo sirven para el retroceso del progreso y cultura de los pueblos".15}

El contexto latinoamericano en el cual Belén inicia su recorrido, se caracteriza por encontrarse en gestación un importante pensamiento liberal progresista que cuestionaba las posturas conservadoras de la Iglesia Católica la que en esos tiempos, además de mantener un fuerte control sobre la enseñanza, los casamientos, nacimientos, etc., imponía un comportamiento ético y moral que afectaba con mayor fuerza a las mujeres. Este clima de presión y restricción permite que se genere un embrionario movimiento femenino que adquiere gran protagonismo social, aun cuando todavía no desarrolla una clara conciencia de demandas de género.

Lo anterior es válido también para nuestro país. La llegada de la conferencista española se da en un ambiente de efervescencia social en el que además del importante movimiento obrero que comienza a gestarse y las luchas dadas por los trabajadores, encontramos un sector de la intelectualidad que apoyaba y solidarizaba con este movimiento y que permitió el surgimiento de una relevante corriente de pensamiento liberal que ponía en el tapete nacional una nueva problemática, la denominada "cuestión social".

No cabe duda que el éxito alcanzado por Belén se apoya en que su llegada se produce en el momento preciso, permitiendo una amplia acogida tanto de la intelectualidad liberal, como del movimiento obrero y los nacientes grupos de mujeres.

${ }^{15}$ Diario El Nacional, 21 de febrero de 1913. 
Respecto al segmento femenino, queda claro que Belén de Sárraga conocía muy bien los derechos de las mujeres. Así, por ejemplo, criticaba con fuerza el hecho que la reforma constitucional española (1890) dejara fuera el voto femenino. Asimismo manifestaba su disconformidad con las injusticias que sufría la clase proletaria y luchaba porque se instalara en el mundo la libertad política y social. Sus argumentos y posición frente al acontecer social, se basaban en las posturas de los teóricos del anarquismo y del socialismo, así como también de los escritos de los grandes pensadores españoles de esos tiempos. Con las lecturas y su experiencia social, ella crea un pensamiento propio que difundirá a través de libros, artículos, folletos y conferencias, y por el cual fue objeto de persecuciones, encarcelamientos e, incluso, intentos de asesinatos (Vitale y Antivilo 2000: 32-34).

Sin duda la prensa de la época, representando las distintas posiciones de la sociedad civil, expresó posturas polarizadas respecto a la llegada de Belén y lo que su presencia significaba. El aspecto común fue que ningún periódico estuvo ajeno a su arribo a Chile; ahora, la cobertura prestada variaba entre aquellos que abiertamente le apoyaban y celebraban sus intervenciones, dentro de los cuales estaban los periódico ligados a las logias masónicas y al partido radical (La Razón, El Sur), al Partido Obrero Socialista (El Despertar de los Trabajadores), a los anarquistas (La Batalla), etc.; y aquellos opositores a su visita, en los que se inscribía toda aquella prensa clerical (La revista Católica, etc.) y, otros de tendencia conservadora, donde también se incluyeron algunos liberales (El Mercurio, El Tarapacá, La Mañana, El Chileno, El Diario Ilustrado, El Día, etc.) (Vitale y Antivilo 2000: 64-65).

\section{"Vomitando bilis}

La llegada de la gran propagandista de la verdad, ha revolucionado a la clerigalla de este puerto.

En todos los antros de la ignorancia y la corrupción, llamados templos o iglesias, los frailes han clamado a sus feligreses no asistir a las conferencias de Belén de Sarraga.

(...) La bilis se le ha revuelto a las sanguijuelas del pueblo y pretenden lanzarla contra una mujer que es la personificación de la verdad pura" (Diario El Bonete 8 de marzo de 1913).

El otro lado de la moneda lo representaban aquellos para los cuales su discurso era nocivo si lo escuchaban aque- llos "hijos del pueblo" con escasa instrucción, ya que podían ser "presa fácil" de sus argumentos.

Vemos entonces que son los liberales, radicales, socialistas, anarquistas y distintos grupos de mujeres, los que seguían la postura de Belén, asistían a sus presentaciones y la ovacionaban en recintos repletos de personas atentas y expectantes a su palabra. En el lado opuesto encontramos al sector conservador, personas apegadas a la Iglesia católica y todas aquellas instituciones clericales (colegios católicos, Universidad Católica, etc.), quienes generan fuertes críticas a sus posturas e, incluso, incitan a sus partidarios a no asistir a los actos.

Durante su permanencia dictó nueve conferencias, las que tuvieron gran publicidad a través de toda la prensa escrita:

$1^{\circ}$ Conferencia: "Trayectorias Humanas"

$2^{\circ}$ Conferencia: "La mujer como entidad social"

$3^{\circ}$ Conferencia: "La Familia"

$4{ }^{\circ}$ Conferencia: "La Moral"

$5^{\circ}$ Conferencia: "Los pueblos y las Congregaciones religiosas"

$6^{\circ}$ Conferencia: "El problema de la Educación"

$7^{\circ}$ Conferencia: "El Jesuitismo y el Porvenir de América"

$8^{\circ}$ Conferencia: "Clericalismo y Democracia"

$9^{\circ}$ Conferencia: "La Iglesia y el Trabajo"

Su primera conferencia causa gran revuelo. Asisten personas de todas las clases sociales y diferentes actividades (intelectuales, de la prensa, juventud, trabajadores, Federación de estudiantes, etc.). Destaca un saludo especial que realiza, dirigido a la mujer chilena, aclarando que son a ellas a las que, en primer término, van dirigidas todas sus intervenciones públicas. Pero es la segunda conferencia, titulada "La mujer como entidad social", la que estaba especialmente estructurada para resaltar la importancia social de la mujer y la necesidad de que ésta se forme intelectualmente para que desarrolle su "temperamento", la "energía" y la "voluntad". Destaca como negativo la visión que se tiene de la mujer y que proviene de aquellas posturas conservadoras ligadas a la iglesia.

Se refiere a los cambios trascendentales que se están dando en el mundo, en el sentido que ya no se busca que la "mujer sea sólo un acicate que acompañe al hombre en la vida", 
pero pese a estas transformaciones aún hay derechos a los cuales la mujer no accede.

Aspectos destacados de esta conferencista española - por adherentes y opositores-, era su gran capacidad de oratoria y elocuencia, como asimismo la audacia para divulgar un discurso contra el clero católico, fuertemente teñido de retórica iluminista. Ahora, esta crítica anticlerical no es que surja sólo con ella, sino que apoya y reafirma el descontento que ya se hacía sentir por parte de un sector de la sociedad, especialmente las clases trabajadoras, frente a una iglesia que representaba un poder asociado a las clases sociales que detentaban el poder político y económico, y que provocaba una gran influencia en la vida familiar y social.

Belén de Sárraga, además de concitar atención por sus discursos anticlericales fue un importante apoyo a la divulgación del pensamiento socialista, a quienes permanentemente saluda y menciona en sus discursos.

Sus presentaciones públicas atraen a una enorme masa principalmente de hombres, pero también de un interesante número de mujeres que participaban atentas de estos entusiastas discursos. No era extraño, dado la efervescencia que provocaba, que sus conferencias terminaran con manifestaciones y enfrentamientos entre sus partidarios/as y sus adversarios/as.

A tanto llegaba la expectación que concitaba que, para evitar los desórdenes callejeros producidos en algunas ciudades, el gobierno se preparaba con anterioridad, precaviendo situaciones incontrolables. Se dice que incluso el regimiento "Carampangue", de Iquique, recibió órdenes de acuartelarse para prevenir posibles desmanes que se produjeran con sus intervenciones públicas en ese puerto.

Durante su estadía en Iquique dictó cinco conferencias que contaron con un respaldo de aproximadamente 2000 personas. En éstas abordó temas tales como "La moral", "Evolución religiosa y del pensamiento", "La mujer como entidad social", "Los pueblos y las congregaciones religiosas", "El Jesuitismo y el porvenir de América", etc.

El paso de Belén de Sárraga por la zona norte se hace sentir, ya que en varias oficinas salitreras que visitó se crearon centros de librepensadores/as. Así, por ejemplo, nace el "Centro Femenino de Lagunas", fuertemente ligado al de Iquique; y en Negreiros, sólo un mes después de su visita, se funda el "Centro de Librepensadoras de la Pampa".

\section{"Un enemigo mas.}

Cerca de un centenar de interesantes mujercitas ha organizado el jueves último un Centro Femenino Anticlerical "Belén de Sarraga".

Han declarado rotas definitivamente sus relaciones con el clericalismo. iQue escándalo! Hay que rogar a Dios que las salve del infierno" (Diario El Bonete, 20 de abril de 1913).

En Iquique, este mismo año nacen algunas "ligas de librepensadores", otras instancias culturales, como el "Grupo de Teatro Arte y Revolución”, y los "Centros Femeninos 'Belén de Sárraga'”, estos últimos influenciados por ella e impulsados por Teresa Flores ${ }^{16}$ y Luis Emilio Recabarren.

Recabarren y la ideología socialista que representaba fue, sin dudas, un factor central en la formación de estos centros y en la incorporación que éstos tienen al proceso de lucha social, llamando a las mujeres a tomar conciencia de su responsabilidad social. Para él la emancipación de la mujer fue una problemática permanentemente tratada y presente en sus discursos. Por otra parte, consideraba la educación un aspecto central para lograr un verdadero crecimiento de la mujer, como asimismo creía que el fanatismo religioso en el que caían las mujeres era tan nocivo como la opresión masculina, por lo que debían liberarse de él.

En este apoyo otorgado por Recabarren al desarrollo de estos centros cabe destacar el periódico El Despertar de los Trabajadores, ${ }^{17}$ a través del cual se difundía gran cantidad

${ }^{16}$ Compañera de Luis Emilio Recabarren, convoca el 10 de abril de 1913 a la formación de un centro femenino.

${ }^{17}$ El Despertar de los Trabajadores era originalmente propiedad de la Sociedad Cooperativa Tipográfica, organizada entre los trabajadores del salitre y ligada al Partido Demócrata, específicamente a la facción obrera liderada por Recabarren. Luego, con la fundación en 1912 del Partido Obrero Socialista (POS) pasa a ser órgano oficial de éste, a partir de la donación que los trabajadores hacen de la imprenta al POS. En 1922 el POS cambia nombre pasándose a llamar Partido Comunista de Chile, convirtiéndose El Despertar de los Trabajadores en su órgano de difusión oficial. 
de artículos y noticias de interés para las mujeres. Mucha información sobre el acontecer mundial, la liberación femenina y las acciones desarrolladas por el movimiento sufragista en el mundo, eran trasmitidas a través de estas páginas, estimulando de esta forma al sector femenino para la lucha por su emancipación:

Las ligas y especialmente los centros los componen mujeres que voluntariamente se comprometen a no vincularse con el clericalismo y sus instituciones. En término de clases, las integrantes de los centros anticlericales son mayoritariamente mujeres proletarias, ya que aquellas mujeres de clase alta dedicaban su tiempo libre a participar en organizaciones vinculadas a la iglesia y su obra social:

\section{"Las ligas de las señoras o la moralidad cristiana}

Las señoras y señoritas de esta ciudad que pasan la vida en eterna desocupación, buscando un medio de matar su aburrimiento y de mover un poco sus miembros, quieren imitar a las de la capital en eso de la formación de 'ligas' y han inventado la sociedad de San Vicente de Paul, para combatir la inmoralidad. [...]

Claro está que la labor moralizadora es altamente digna de elogio y desde estas columnas aplaudimos a las señoras y a las ligas [...]" (Diario El Bonete, 14 de julio de 1912).

La primera organización de mujeres creada como resultado de la presencia de Belén se llamó "Centro Belén de Sarraga de Señoras Librepensadoras" y lo encontramos en Antofagasta el 4 de abril de 1913; estaba conformada por alrededor de 40 mujeres. Esta iniciativa de las mujeres antofagastinas motiva a las de Iquique a seguir sus pasos. Es Teresa Flores y apoyada por el periódico El Despertar de los Trabajadores, quien invita a las mujeres a crear la organización, encontrando una entusiasta acogida por parte del elemento femenino más ilustrado del puerto de Iquique.

Así, el 17 de abril de 1913 se crea el "Centro Femenino Anticlerical y de Libre Pensamiento 'Belén de Sárraga'”. El Comité administrativo estaba conformado por: Ana Guzmán (Secretaria), Rosario V. de Barnes (Tesorera), Zoila Zepeda de Toro, Pabla R. de Aceituno y Juana Alvarado de G. (Vocales). El estatuto que les regía resaltaba el carácter voluntario de la integración de sus socias, su nula vinculación con todo lo referido al clericalismo, compromiso de propagar los pensamientos del Centro a otras mujeres, buscar compartir su vida matrimonial con un librepensador, pago de cuota mensual, difusión de sus ideales a través de acciones públicas, etc. Su declaración de principios recalcaba el anticlericalismo y la propagación de la doctrina del libre pensamiento. Tenían como objetivos doctrinarios la liberación de la mujer de cualquier tipo de opresión, fuera esta principalmente religiosa o masculina, como asimismo inculcarle la toma de conciencia sobre su responsabilidad social.

Vemos cómo su acción se orientaba hacia la lucha laicista, pero también se incorporan al proceso de lucha social que se desarrollaba en la zona del salitre denunciando problemas regionales tales como el alcoholismo, la carestía de la vida, el derecho al descanso dominical, preocupándose por los efectos de la Primera Guerra mundial y divulgando las ideas de emancipación de la mujer. Con el tiempo pasarán a formar parte activa del llamado feminismo de izquierda que promoverá el Movimiento Pro Emancipación de la Mujer Chilena (MEMCH).

Así, luego de la fundación, la mujeres que participan del Centro Femenino comienzan a tomar parte en actividades públicas, entre las cuales destacan las relacionadas con del movimiento obrero y del Partido Obrero Socialista, con los cuales están vinculadas por la presencia de Teresa Flores y el apoyo de Luis Emilio Recabarren.

"La vida en la Pampa. Oficina Lagunas. Conferencia socialista Para el sábado cinco y domingo seis de julio se ha organizado una serie de conferencias en este pueblo, a las cuales se invita a los trabajadores de toda las oficinas cercanas (...) Irán de Iquique a tomar parte en estas conferencias el compañero Luis Emilio Recabarren, las compañeritas del centro femenino Teresa Flores, Rebeca Barnes y Teresa Veliz" (Diario El Despertar de los Trabajadores, 19 de junio de 1913).

A los pocos días de la fundación del Centro Femenino es aceptada su participación, a través de dos delegadas, en la "Cámara del Trabajo", institución que reunía diversos gremios y oficios en la ciudad de Iquique.

Los Centros Belén de Sárraga desplegaron una actividad de gran magnitud que, para muchos estudiosas/os, no ha podido ser igualada en otros momento con condiciones mucho más favorables de desarrollo político y social de 
las mujeres. Durante el primer año de funcionamiento realizan 36 reuniones generales, 8 veladas y conferencias; asisten en grupo a 24 manifestaciones públicas en Iquique y en la Pampa; participaron en 68 actos públicos, forman parte de la Cámara del Trabajo, etc. Además tenían una permanente presencia pública participando en las festividades que la comunidad iquiqueña celebraba tradicionalmente. También realizaron una gran labor difundiendo sus ideas mediante folletos y documentos impresos, como a través de artículos insertos principalmente en los periódicos El Bonete y El Despertar de los Trabajadores.

Así, mientras dura la actividad de estos Centros podemos hablar de una gran movilización de la mujer pampina, todas juntas luchaban por difundir la importancia de la emancipación femenina. No estaban solas, había una fuerte conexión con los partidos de izquierda, proletarios, que planteaban el problema de la opresión de la mujer al lado de la del obrero.

Ahora, un tema por investigar en profundidad es el motivo por el cual en los años venideros los partidos de izquierda, ya más desarrollados ideológica y orgánicamente, dejan fuera esta postura que busca denunciar situaciones de opresión que aún se viven con fuerza. Incluso es más, el propio feminismo de izquierda que en la década de los años 1930 se constituye a través del $\mathrm{MEMCH}$, desecha la posibilidad de derivar en una organización política autónoma que mantenga y siga con la línea reivindicacionista feminista, disolviéndose una vez alcanzado el voto (Kirkwood, J. 1990: 111).

El auge de estos centros se da entre los años 1913 y 1915. Esta última fecha coincide con la segunda visita de Belén a Iquique, el 18 de junio de 1915, momento en el que nuevamente es recibida por una multitud que la vitorea y aplaude, ansiosa de volver a escuchar su palabra libertaria. Pese a lo anterior, el ambiente no tiene la misma efervescencia que en su primera estadía. En Iquique dicta cinco conferencias: "El peligro de América", "La guerra y la religión", "Jesús y sus ministros", "La Iglesia en la política", "Hasta más allá de la tumba".

Su presencia provoca la reactivación de las organizaciones femeninas que estaban un tanto aletargadas y la creación de otras nuevas. Por ejemplo en este año (1915) aparece el Centro de Librepensadoras y Auxilios Mutuos 'Belén de Sárraga', que a diferencia de otros centros se dedicó fundamentalmente a la creación de una escuela nocturna, que impartía educación gratuita y contaba con una sección especial para niñas:

"Escuela Nocturna del Centro de Librespensadoras Belén de Sarraga

Las clases nocturnas son de instrucción primaria y se llevan a cabo todas las noches de 7 a 9 p.m. en excepción del día sábado. La sección niñas está a cargo de la señora Isabel G. de España, profesora titulada [...] La instrucción que se da en esta escuela es absolutamente gratis".18

Con todo, la mayoría de los Centros femeninos anticlericales y de libres pensadoras que se crean en la zona norte, se caracterizan y diferencian de las instancias organizativas de mujeres que surgen en esta misma época en Santiago, en términos de clase, liderazgo y objetivos. Su decadencia y desaparición se observa hacia 1918, producto de la migración de mujeres, en especial de dirigentes del movimiento, hacia centros urbanos por las crisis cíclicas de la industria salitrera; por las tensiones del movimiento obrero; y también, principalmente, por el desplazamiento que las mujeres realizan hacia nuevas formas de organización, tales como los partidos y los sindicatos, que se imponían en los sectores populares en la década de los años 1920 y que proliferan en la década de los años 1930 .

\section{* Otras formas de organización femenina}

Otras formas de organización que se dieron las mujeres y que funcionaron paralelas a los últimos años de actividad de los Centros Femeninos, estaban ligadas principalmente al Partido Socialista. Dentro de estas podemos mencionar el "Centro de Mujeres Socialistas" creado en Iquique en 1915; el "Centro de Mujeres Socialistas" fundado en 1916 en Antofagasta; y el "Centro Instructivo de Obreras Librepensadoras 'Luisa Michell'”, creado en Antofagasta en julio de 1916. Estas organizaciones tenían en común el propósito de instruir, educar y capacitar a la mujer ya que de esta forma consideraban que era posible elevar el nivel moral e intelectual de los individuos y de

${ }_{18}$ Diario El Despertar de los Trabajadores, Iquique 6.10.1916. 
los pueblos, apoyando de esta forma los esfuerzos que los hombres socialistas estaban realizando y dejando de manifiesto la importancia que se le asignaba a la educación e instrucción de la mujer.

Llegamos luego a la década de los años 1920 donde aparecen una serie de organizaciones e instancias que llaman a agruparse y participar de manera activa a las mujeres obreras de las ciudades y oficinas salitreras de la pampa nortina. La totalidad de las organizaciones de este tipo que surgen se adhieren sea a la IWW o a la FOCH, formando parte de Consejos, Secciones o Federaciones Femeninas.

Dentro de la Internacional de Trabajadores (IWW), se llamaba a las mujeres obreras a federarse para "luchar contra los abusos del capital', encontramos en 1921 la "Federación Obrera Femenina" y la "Federación Obrera Femenina de Oficios Varios"; las que en el mes de marzo de ese año, acuerdan su unificación pasando así a conformar la "Federación Unión Obrera Femenina", siendo su primer directorio el siguiente:

\section{"Federación Unión Obrera Femenina. Nuevo directorio}

Esta organización en reunión celebrada el 16 del presente nombró el siguiente directorio.

Secretaria General: Elena G. de Ramirez.

Secretaria de Actas: Juana Castillo.

Tesorera: Rosa R. de Castillo.

Recaudadora: Carmen Benits.

Directoras: Juana Caza, Juana Lobos, Manuela Castillo" (Diario El Despertar de los Trabajadores, 22 de junio de 1921).

Por su parte, dentro de la Federación Obrera Chilena (FOCH), con Recabarren a la cabeza, se crean una serie de instancias dependientes de esta federación y que permiten la organización de las mujeres, tanto en las ciudades como en las Oficinas salitreras.

La primera de estas organizaciones creadas en el seno de la Federación Obrera de Chile fue el "Consejo Federal Femenino", fundado paralelamente en Iquique, Santiago y Valparaíso, en 1917; su finalidad era lograr el mejoramiento cultural y la acción mancomunada de las trabajadoras. Sesionó hasta 1918, reapareciendo en 1920 con el nombre de "Gran Federación Femenina de Chile", con reivindicaciones de carácter más feministas (Gaviola, E. op. cit. 1986: 35).
Otras de estas instancias son, por ejemplo, el "Consejo Federal Femenino $\mathrm{N}^{\circ} 13$ ”, "Consejo Femenino $\mathrm{N}^{\circ}{ }^{1}$,, "Consejo Femenino N ${ }^{\circ} 17$ de Oficios Varios", "Consejo Femenino de Gloria", "Consejo Femenino $\mathrm{N}_{4}^{\circ}$ de Alto San Antonio", "Consejo Femenino de Propaganda de Huara", creadas en 1921, etc. Con posterioridad, especialmente 1923 y 1924 encontramos en plena actividad las Secciones femeninas, ligadas a los Consejos de las distintas especialidades laborales y con asiento en las Oficinas: "Sección Femenina de Huara", "Sección Femenina de Alto San Antonio del Consejo Industrial de Minas de Alto San Antonio", "Sección Federal Femenina", "Sección Femenina del Consejo Industrial de Minas de Huara", "Sección Federal Femenina de Buena Ventura", "Sección Femenina de Bellavista", etc.

Estas organizaciones, antes mencionadas, representan las dos principales corrientes ideológicas que caracterizaron la lucha obrera de Chile como lo fueron la anarquista y la socialista. Ambas organizaciones pusieron su énfasis en el ámbito social y político más que en lo legal y educativo. Aun cuando el acceso a la instrucción, comienza a constituirse como una de las reivindicaciones más sentidas, presentes en el período que se inicia.

Con posterioridad y terminando el período que en este capítulo nos ocupa, las organizaciones femeninas se ven absorbidas por las nuevas expresiones socio-políticas dominantes, los partidos políticos y los sindicatos obreros, especialmente por la labor que comienza a desarrollar el Partido Comunista.

\section{$*$ Conclusiones}

Si bien en las primeras décadas del siglo XX encontramos en el ambiente nacional una fuerte influencia de ideologías externas que plantean y propician la existencia de una sociedad más igualitaria, también es posible identificar ciertos factores particulares y locales que habrían facilitado el movimiento de mujeres en el norte salitrero.

Producto de la actividad salitrera, se genera en el norte de Chile una concentración de obreros y sus familias, en un contexto de vida cotidiana que permite la reunión de las mujeres en torno a problemas compartidos en su condición de clase, que luego desembocan en problemas de 
discriminación más específicos, como los de género. Al panorama anterior, debemos sumarle que en esa época se produce un gran desarrollo del movimiento obrero en la zona salitrera, que posibilitó la participación de las mujeres en las protestas, huelgas y manifestaciones en pro de los derechos de sus parientes masculinos. Además, tenemos el surgimiento del Partido Obrero Socialista (POS) en 1912, el cual desplegó una interesante actividad de difusión hacia la mujer, promoviendo el desarrollo intelectual de ésta y su participación en organizaciones, todo esto bajo la orientación de Luis Emilio Recabarren. Una especial llegada ideológica entre las mujeres de la zona norte la tuvo la presencia en Chile de la española Belén de Sárraga, que alentó a las mujeres a organizarse y dar vida a la reivindicación emancipatoria.

Vemos como las mujeres empiezan a incorporarse a las luchas sociales, dentro de un contexto social convulsionado donde el movimiento obrero lleva la "bandera de lucha" y les invita a participar. En este nuevo escenario, las mujeres tuvieron dos opciones, asumir un papel de acompañantes para apoyar las reivindicaciones de los hombres; o intentar diferenciar la lucha femenina, articulando la opresión de género y de clase.

De manera paralela e independiente al movimiento antes mencionado, que fue denominado "feminismo obrero", encontramos otras instancias organizativas femeninas, tales como las Sociedades Mutualistas o de Socorros Mutuos, las Mancomunales.
El punto fuerte en lo referido ha acciones femeninas colectivas, lo tenemos con la constitución de los Centros Belén de Sárraga, que corresponden a las primeras expresiones formales de mujeres organizadas a nivel nacional que tratan temas que problematizan los roles masculinos-femeninos. Estas instancias organizativas tuvieron como propósito central liberar a las mujeres del "fanatismo religioso" en el que se encontraban y de la "opresión masculina" de que eran objeto; como asimismo, apoyarles para formar una conciencia clara sobre su responsabilidad social. Vemos, entonces que no sólo se limitaron a la lucha y la práctica laicista, ya que se incorporan en el proceso de lucha social que se desarrollaba en la zona salitrera.

Finalmente, podemos concluir diciendo que las mujeres se ubican en la historia y la sociedad producto de las relaciones de género. Ahora, durante el lapso considerado en el estudio, se dieron una serie de sucesos coyunturas, factores, acontecimientos históricos, etc. que permitieron modificaciones en las relaciones de género - así como también ocurrió con otras relaciones sociales- pero en éstas, los principales cambios se dan producto de la actuación de las mujeres, diversas, heterogéneas, pero organizadas bajo distintos pero concretos objetivos.

Agradecimientos Este trabajo cuenta con el apoyo del Convenio de Desempeño Universidad de Tarapacá Mineduc.

\section{* Referencias citadas}

\section{Publicaciones periódicas}

- Diario El Trabajo, Iquique 05.04.1902; 09.08.1902; 30.08. 1902.

- Diario El Trabajo, Iquique, 08. 08.1903

- Diario El Proletario, Tocopilla, 01. 06.1906.

- Diario El Despertar de los Trabajadores, Iquique 27.01.1912; 13.06.1912; 23.01.1913; 19.06. 1913; 06.10.1916; 22.06 .1921$.

- Diario El Nacional, Iquique 21.02.1913; 20.10.1913.

- Diario El Tarapacá, Iquique18.05.1924; 16.07.1924.

- Diario El Bonete, Iquique 14.07. 1912; 08.03.1913; 20.04.1913.

\section{Fuentes orales}

Entrevista Sra. E. S. Iquique, 1987. Entrevista Sra. S. M. Iquique, 1987. Entrevista Sra. A. L. Iquique, 1987. Entrevista Sra. M. Á. C. Iquique, 1987.

\section{Publicaciones}

CÁCERES, M. 1938. Las Sociedades de Socorros Mutuos ante la Legislación Chilena. Imprenta Cervantes, Santiago de Chile. 
CARRASCO, A. M. 2007. Hacia un nuevo significado de la política: Los movimientos de mujeres en la región de Tarapacá, Chile (1910-1973). Tesis doctoral. UBA, Barcelona.

CASTRO, L. 1994. Las mujeres y su realidad en la industria salitrera. En Tarapacá: Una aventura en el tiempo. Camanchaca, ediciones especiales Camanchaca 6:34-40.

CONTE, R. 1987. La Mutualidad Femenina: Una visión Social de la Mujer Chilena. 1888-1930. Tesis para optar al grado de Licenciatura en Historia, Universidad de Chile, Santiago de Chile.

CRUZAT, X. 1980. Las Mancomunales en el norte salitrero: 19011907. En Seminario la Visión de Mundo del movimiento mancomunal en el norte salitrero entre 1901 y 1907. Academia de Humanismo Cristiano. Santiago de Chile.

1981. El movimiento mancomunal en el norte salitrero: 1901- 1907. Tomo I, II y III. Beca de investigación CLACSO, Santiago de Chile.

GAVIOLA, E. 1986. Queremos votar en las próximas elecciones. Imprenta Arancibia Hermanos, Santiago de Chile.

GONZÁLEZ, S. 2002. Hombres y mujeres de la Pampa. Tarapacá en el ciclo de expansión del salitre. Ediciones LOM, Santiago de Chile.

1991. Hombres y mujeres de la Pampa: Tarapacá en el ciclo del salitre. Ediciones Camanchaca, TER, Iquique.

HUTCHISON, E. 1992. El feminismo en el movimiento obrero chileno: la emancipación de la mujer en la prensa obrera femenina, 1905-1908. Proposiciones: Género, Mujer y Sociedad. Ediciones SUR. Santiago de Chile.

1995. La defensa de las 'hijas del pueblo' Género y política obrera en Santiago a principios de siglo. En Disciplina y Desacato. Construcción de Identidad en Chile, Siglos XIX y XX, L. Godoy, E. Hutchison, K. Rosemblatt y S. Zárate, pp. 257-285. SUR/CEDEM. Santiago de Chile.
KIRKWOOD, J. 1987. Feminarios. Documentas, Santiago de Chile.

1990. Ser política en Chile. Los nudos de la sabiduría feminista. Editorial Cuarto Propio, Santiago de Chile.

LUNA, L. G. 1994. Historia, género y política. En Historia, género $y$ política. Movimientos de mujeres y participación política en Colombia, 1930-1981, SIMS, Universidad de Barcelona, pp. 19-58. España.

1995. Los movimientos de mujeres en América Latina o hacia una nueva interpretación de la participación política. Boletín Americanista 45: 249-256.

1996. La otra cara de política: Exclusión e inclusión de las mujeres en el caso Latinoamericano, Boletín Americanista 46: 153-159.

ORTIZ, A. 1985. El Movimiento Obrero en Chile (1891-1919). Libros del Meridión, Ediciones Michay, Madrid.

SALINAS, C. 1987. La Mujer proletaria: Una historia por contar. Literatura Americana Reunida, LAR, Concepción.

SCOTT, J. W. 2000. El género: una categoría útil para el análisis histórico. En El género. La construcción cultural de la diferencia sexual, M. Lamas (Comp.), pp. 265-302. PUEG, Universidad Nacional Autónoma de México, México.

1990. El género una categoría útil para el análisis histórico. En Historia y Género, J. S. Amelang y M. Nash (Ed.), Alfons el Magnánim, Valencia.

VALDÉS, T. 1994. Movimiento de mujeres y producción de conocimientos de género: Chile 1978-1989. En Mujeres y participación política. Avances y desafíos en América Latina, M. León (Comp.), pp. 291-292. TM Editores, Bogotá, Colombia.

VITALE, L. 1981. Historia y Sociología de la Mujer Latinoamericana. Editorial Fontamara. Barcelona. 